\title{
Difficulties Encountered in Collaborative Care: Logistics Trumps Desire
}

\author{
Frances Legault, RN, PhD, Jennie Humbert, NP-PHC, MHSc, Stephanie Amos, PhD, \\ William Hogg, MD, MSc, Natalie Ward, MA, PhDc, Simone Dabrouge, PhD, MSc, \\ and Laura Ziebell, MSC
}

Introduction: This study examines the development of collaborative relationships between family physicians (FPs) and Anticipatory And Preventative Team Care (APTCare) team members providing care to medically complex patients who have been identified as at-risk for negative health outcomes.

Methods: We undertook a qualitative study of a primary health care intervention in a family practice. Interviews were held with FPs and ATPCare intervention nurse practitioners (NPs) and pharmacists. Focus groups were conducted and a survey was administered to participating FPs, NPs, and pharmacists. NPs and pharmacists maintained a log recording their tasks and moments of collaboration.

Results: Scheduling demands rendered face-to-face collaboration difficult, leaving the team to rely on technological tools to keep in touch. Limited space meant the APTCare team had to work out of a downstairs office, limiting informal interactions with the practitioners on the main level.

Conclusions: We demonstrate that the difficulties inherent in collaborative care are independent of the patient population being cared for. Regardless of the patient population and sector of health care, developing collaborative relationships and learning to work collaboratively is difficult and takes time. What many of these teams need is ongoing support and education about how to make these collaborative care practices work. (J Am Board Fam Med 2012;25:168-176.)

Keywords: Collaboration, Health Care Team, Interprofessional Relations, Primary Health Care

Reforming primary care service delivery has become a high priority in Canada. Team-based primary health care is becoming increasingly important in Canada, ${ }^{1}$ where ongoing reforms have increasingly invested in the provision of interpro-

\footnotetext{
This article was externally peer reviewed.

Submitted 1 May 2011; revised 30 November 2011; accepted 12 December 2011.

From the Ontario Primary Health Care Nurse Practitioner Program (FL), the Department of Family Medicine (WH, SD), and the Department of Anthropology and Sociology (NW), University of Ottawa, Canada; West Nipissing Community Health Centre, Sturgeon Falls, Canada (JH); the Regional Geriatric Program of Eastern Ontario, The Ottawa Hospital, Canada (SA); C.T. Lamont Primary Health Care Research Centre, Elisabeth Bruyère Research Institute, Ottawa, Canada (WH, NW, SD); and the Children's Hospital of Eastern Ontario, Ottawa Children's Treatment Center, Canada (LZ).

Funding: Funding for this research was provided by the Ontario Ministry of Health and Long-Term Care Primary Health Care Transition Fund.

Conflict of interest: none declared.

Disclaimer: The views expressed in this report are the views of the authors and do not necessarily reflect those of the Ontario Ministry of Health and Long-Term Care.
}

fessional primary health care services, ${ }^{2,3}$ a primary health care reform that has also spanned the globe. ${ }^{4-6}$

As a new model of care provision, team-based care increasingly has become the focus of health services delivery research. An examination of the literature about collaborative teams across many sectors of health care has found that studies have demonstrated the effectiveness of collaboration on the provision of better patient care, ${ }^{7,8}$ improved clinical outcomes, ${ }^{9,10}$ improved patient satisfaction, ${ }^{11}$ and enhanced job satisfaction. ${ }^{12,13}$ Collaborations between physicians and pharmacists or nurses have been shown to increase medication adherence significantly, ${ }^{14}$ improve patient outcomes and prevent medication errors, ${ }^{15}$ decrease

Corresponding author: Frances Legault RN PhD, Ontario Primary Health Care Nurse Practitioner Program, University of Ottawa, 600 Peter Morand Crescent, Suite 101, Ottawa ON K1G 5Z3, Canada (E-mail: flegault@ uottawa.ca). 
hospital visits, and increase understanding of interprofessional roles. ${ }^{16}$

The literature about health care teams has provided a clear understanding of characteristics of well-functioning teams: the necessity of clear definitions of roles ${ }^{17,18}$; the need for effective and clear communication ${ }^{19-21}$; and the role of trust and appropriate education. ${ }^{22}$ Several factors that inhibit successful collaboration also have been identified. These include a lack of understanding of roles, ${ }^{23,24}$ knowledge, and responsibilities; cultural differences between professions ${ }^{25}$; differing perceptions of teamwork ${ }^{22,26-28}$; and power differentials created by the dominance of medical power. ${ }^{29}$ In addition, it has been noted that work overload can impede interdisciplinary cooperation, and confusion about role boundaries and expectations can decrease quality of care. ${ }^{30-32}$ Other barriers include time limitations, ${ }^{33,34}$ lack of efficient communication, ${ }^{23,24,31,35,36}$ a lack of trust and respect, ${ }^{37}$ and geographic separation that promotes working in "silos." 38

Barriers and facilitators of team-based collaboration have been identified, ${ }^{18,39-42}$ but no reports were found about collaborative teams in which the nurse practitioner (NP) and pharmacist were simultaneously added to the team with the intention of caring for the most complex patients in the practice. This study is part of the Anticipatory and Preventive Team Care (APTCare) project, which examined the impact of a multidisciplinary clinical team on the care of patients most at risk in a family practice. This article focuses on describing the development of a collaborative relationship among the APTCare team members (NPs and a pharmacist) and family physicians in a model of service delivery in which physicians are remunerated principally by capitation and all other personnel are salaried.

\section{Methods}

\section{Design}

The APTCare study was a mixed-methods randomized controlled trial that compared the outcomes and experiences of at-risk patients who were provided with anticipatory and preventive team care with patients who received usual care (1:1). The study was approved by the Ottawa Hospital Research Ethics Board and is registered with CONSORT as NCT00238836.

\section{Setting}

The study was conducted from 2004 to 2006 in a rural family practice (Ontario, Canada) that had been in operation for more than 25 years. In 2004, the practice had adopted the capitation-based model and had a roster of 7500 enrolled patients. The practice included 8 family physicians (FPs; 6 full time and 2 part time), 5 nurses, and administrative personnel. Physicians were remunerated principally through capitation but also received a fee-for-service component, bonuses, and incentives. Electronic medical records (EMRs) had been fully implemented in the practice since January 2002.

\section{Study Population}

The target population included patients 50 years of age or older who were enrolled to the practice and who were identified by their physicians as being among the most at risk of experiencing adverse health outcomes and would benefit from additional support. Patients with significant cognitive impairment, language/cultural barriers, life expectancy of less than 6 months, or who were expected to be away for a duration of 6 weeks or more during the study period were excluded.

\section{Recruitment}

Details of the study methodology are provided in a companion article. ${ }^{43}$ Briefly, a review of the literature established links between common risk factors and vulnerable populations. ${ }^{16,44-49}$ Patients possessing several of the identified risk factors (emergency department visit during the past year, multiple health issues including at least 2 chronic conditions, at least 5 visits to the practice in the previous 6 months or 10 in the previous year, polypharmacy) were identified by the research team via the practice's EMR system. This process produced a list of 1009 potential participants. A summary profile of each potential participant was created and reviewed by the respective FPs for screening to ensure those individuals who were cognitively impaired or who were in palliative states or otherwise did not meet the inclusion criteria for the study were not approached. Physicians coded patients as at a high, medium, low, or very low risk level. Three hundred eighty-three patients were determined to be high or medium risk and were suitable for inclusion in the study. Twelve patients were not identified through the process 
described earlier but were identified separately by the physicians as being at risk. Patients were excluded primarily owing to a planned prolonged absence during the winter, because they refused or could not be contacted. In total, 241 patients participated and 120 were randomized during their baseline home visit to the experimental arm of the study. Recruitment of patients took place between October 2004 and March 2005 and all patients were followed until March 31, 2006, for a total intervention duration of 12 to 18 months (mean, 14.9 months in each arm). The overall participation rate was $77 \%$.

\section{Intervention}

The clinical APTCare team consisted of 3 parttime NPs and one pharmacist. The pharmacist worked full-time for the first 9 months and one NP worked full-time for 5.4 months, after which all worked part-time. During the 18-month study, care by the pharmacist and NPs was provided primarily in the patients' homes and through telephone contact, with occasional clinical visits occurring at the practice site for follow-up care. The patients continued to see their personal physician when needed. The NPs were actively involved in the team for the duration of the study (18 months). The pharmacist's role was discontinued after patients were assessed and an appropriate action plan had been set in place (15 months). Further details regarding the APTCare intervention are provided in other publications. ${ }^{43,50}$

\section{Data Collection}

Data regarding collaboration were collected from the APTCare team, physicians, and family practice nurses at the beginning, midpoint, and end of study through a mix of qualitative and quantitative means.

\section{Qualitative Data Collection}

Seven focus groups were convened, including the APTCare team (2 groups), practice physicians (2 groups), the APTCare team and the practice physicians (one group), all practitioners (one group), and practice nurses only (one group). The Jones and Way Collaboration Care Provider Survey, ${ }^{51}$ administered to evaluate differing aspects of collaboration between practitioners, was used to develop focus group questions, which included how challenges in collaboration were being addressed, issues of responsibility and coordination of care, communication, and the development of trust and respect.

Interviews (10 in total) with the pharmacist and NPs were conducted at the project midpoint, and interviews with pharmacist, NPs, and family practice physicians were conducted at the midpoint and at the end of the study. Midpoint and exit interviews focused heavily on providers' satisfaction with their role and the way that their role is developing within the team, satisfaction with the care and services they have been able to provide, and the amount of contact they have had with the patients. They also explored processes and strategies for communication and feedback, satisfaction with the way collaboration has been progressing, and how collaboration might be improved. Exit interviews also sought to capture how the practitioners would develop their role in the future if they were continuing on in the practice.

\section{Quantitative Data Collection}

A collaboration survey based on the Jones and Way Collaboration Care Provider Survey ${ }^{51}$ was administered to the FPs, NPs, and the pharmacist involved in the project. These surveys collected demographic information on sex, age, education, experience, method of payment, and previous experience working collaboratively. Practitioners were presented with 2 sections consisting of Likert scale questions, with a focus on their current experience of collaborative practice: (1) 9 items measuring experience of current collaboration (do practitioners collaborate on decision making, show trust and respect, communicate openly, and plan together?); and (2) 11 items measuring provider satisfaction with the collaborative experience, including shared planning, communication, decision making, trust and respect, and amount of communication. Surveys were distributed to the practitioners by the research team and were picked up at a later time. Reminder emails were sent to any practitioner who had not submitted their completed survey to the research team.

Daily logs were maintained by the APTCare team members throughout the study period to contribute to our understanding of some of the aspects of formal collaboration that takes place among an interprofessional team. These logs, recorded in Excel (Microsoft Corp., Redmond, WA), tracked the number of days/hours worked, amount of formal collaboration occurring during days worked, individuals involved in and the nature of formal collab- 
orations, positive and negative aspects of collaboration, and methods used to deal with these negative aspects. Logs were emailed to the research team on a monthly basis and data were collected and tabulated at that time. The logs were completed and did not having missing entries.

\section{Data Analyses}

Qualitative Analysis

All interviews and focus groups were recorded, transcribed, and entered into the NVivo software program (QSR International, Doncaster, Victoria, Australia). ${ }^{52}$ The project team employed an iterative analytical strategy of constant comparison ${ }^{53,54}$ through which investigators and researchers reflected on the data as it was collected. This enabled the team to make ongoing changes to the intervention and to refine the data collection instruments. Searches were made for disconfirming cases, ${ }^{53}$ and ongoing refinement of major themes associated with roles, communication, and collaboration were identified and incorporated into the evaluation. To ensure consistency, the research team held regular meetings that involved discussion of coding categories and analysis of data. Member checking was used to verify results. Results that were acquired from comment boxes included with the surveys and comments submitted with the practitioner logs were reviewed and organized according to similarity.

\section{Quantitative Analysis}

Collaboration survey. We assessed 2 dimensions: the extent of collaboration (9 questions) and satisfaction with collaboration (11 questions). Answers were on a Likert scale of 1 to 7 , representing the least and highest extent of satisfaction with collaboration, respectively. Overall scores were derived by summing the total number of answers selected for each scale category, multiplying that number by its scale value, and dividing the sum of these by the number of responses. Overall scores, therefore, represent the average score out of a possible score of 7 .

Practitioner logs. Quantitative data from the practitioner logs was collected and entered into a data management program. Numbers presented represent the summative and ranged data collected over the 5-month time frame.

Triangulation. Triangulation of the results from the focus groups, interviews, collaboration surveys, and practitioner logs ensured a compre- hensive understanding of the data and revealed no disjunction between data sets. In addition, to increase rigor, investigator triangulation was used to reduce biases from a single interviewer. ${ }^{55}$

\section{Results}

\section{Learning to Collaborate}

Before the study, FPs working in the Family Health Network had minimal experience working collaboratively with NPs or pharmacists. Practitioners, particularly the FPs and NPs, found learning to work together to be a difficult process. Daily logs filled out by NPs and the pharmacist reveal that the APTCare team struggled with issues related to professional roles and responsibilities, including perceived physician reluctance to assign tasks to the team. Practitioners worked through this by building a strong rapport with physicians by providing strong rationale for decisions made by the team. Interviews suggest that it took approximately 6 months for the team to understand each others' areas of competency and to recognize how the practitioners could work together. Despite having been formally presented with the role and scope of practice at initiation of the study, it was only through direct interaction in the context of client care that physicians were able to appreciate clearly the roles, scope of practice, and individual strengths of the APTCare team members.

As the study progressed, the division of responsibility among the NPs, pharmacist, and physicians became clearer and APTCare team members felt an acknowledgment of professional opinions between all team members, including the family practice physicians. Results from the Collaboration Survey show that physician satisfaction with collaboration and the extent of collaboration with NPs and the pharmacist grew over time and, by the midpoint of the study, the physicians remarked on the added value of having NPs as part of a patient care team, noting that the NPs were better at "scoping out services available in the community and connecting the patient with services," rendering access to needed patient resources more quickly and effectively.

The pharmacist was also found to be "invaluable" by both NPs and physicians. The pharmacist worked predominantly onsite full time, and early in the study both NPs and physicians saw the benefit of having access to pharmacological services. In 
fact, physicians had to remind themselves to access the pharmacist's services only for their intervention patients. One physician mentioned that the pharmacist “. . . can bring insight into what's in the patient's home. Having the pharmacist do the home visit is also helpful because she can go through the medicine chest and give us a sense of what drugs they're really taking versus what they tell us...And going through the chart in a very structured way and looking for gaps, which is different from the way we usually do things."

\section{Coordinating Care as a Team}

Learning to work with each other was complicated by having to learn how to coordinate care as a team. Initially, the project team thought it would be beneficial to have regular meetings with physicians to develop a working relationship, but this proved difficult because of scheduling demands. NPs were frequently offsite doing in-home visits, making it challenging to develop a relationship with FPs and each other. Initially, building a relationship with the pharmacist was facilitated through her position as a full-time employee on the team. This full-time status meant that there was greater opportunity for informal collaboration. Practitioner logs revealed that the team attempted to deal with these issues by making sure significant advance notice of meeting times was issued to avoid scheduling conflicts, sending out care plans with targeted areas highlighted to maximize efficiency, and establishing a phone messaging system to maintain contact with physicians.

At the time of the study, the NP role was still quite new and the legislated role was more limited than it is now. The role of NPs working with patients who were among the most ill in the practice was an innovation tested in the APTcare study. Initially it was felt that specific care protocols such as medical directives would be beneficial for team function. Given the study's short time frame and the difficulty the team had coming together for meetings, however, the NPs decided not to pursue this route. Instead, they took the initiative to document processes on dispensing and reordering medications. Having the medical directives in place might have assuaged the concerns of other practitioners, like those of one physician in particular who used the personal comments section of the Collaboration Survey to comment, on several occasions, about their concerns regarding the legal responsibility of decision making (who is ultimately responsible).

Addressing the issue of medical directives and further conversations about responsibility early on in the process might have prevented some frustrations experienced later. Personal comments posted in the survey indicated that FPs and NPs were still working out their roles at the 9-month mark and it was clear that, although collaboration was their intent, FPs expected that the NPs and pharmacist to be mostly independent. On this note, one physician noted that they would like to see NPs do more of their own follow-up, rather than noting additional items in the patient's chart with the expectation that the physician would do it during the next visit. This may also have something to do with the frequency with which tests ordered by the NPs came back in the physician's name: "I was just thinking that if an NP orders something under a physician's name, to put in additional comments, such as ordered by, so we would know [who ordered it]."

Indeed, the short time frame of the project and competing demands on practitioners meant that collaboration as the ideal practice was not always attained and interpersonal issues were not always addressed or resolved. Among NPs, one stated in the 9-month survey that she strongly disagreed that they "planned together to make decisions about the care for patients "; she continued her thoughts in the comment box, noting "strongly disagree-We have independently managed our own patients."

\section{Communicating as a Team}

Although our practitioners did not have as many formal case conferences as they had originally thought they might, comments included in the practitioner logs indicated that they appreciated the opportunity for dialogue and problem-solving opportunities that the case conference meetings allowed. In addition to fewer meetings, the APTCare team found that they had little opportunity for casual face-to-face interactions with the other practitioners in the building. The team was situated in the finished basement beside the laboratory and radiograph facility and as one physician said, "It's not my habit to go downstairs very often, so my communication is via the 'To Do' list. It might be helpful just to walk into the office, without that barrier [of being on a different floor separated from other practitioners]." This geographic separation in combination with their part-time status and frequent home visits also 
meant that the NPs and pharmacist were not always available for face-to-face communication. As such, they relied primarily on the electronic "To Do" system or telephone messages.

The electronic To Do system is a secure, internal clinic electronic communication system through which messages can be sent from one clinic member to another (clinicians and support staff). The To Do note can be created from within a patient chart and thus is the legal document archiving communications and actions as individuals respond to the inquiries. The To Do note also can be created independently and not be linked to any particular patient's file. The dependence on this electronic system as a tool of communication created limitations for the APTCare team and the physicians they were collaborating with because the system did not allow for a dynamic care plan. The Clinical Improvement System platform that hosts the To Do is constructed to offer a way to organize the many elements that would be included in a paper chart but does not provide the means of adjusting the care plans created by the APTCare team. Instead, the manually devised plan was scanned into the EMR system and remained static. As a result, current information was not always available for all care providers to review, hindering team member communication.

\section{Discussion}

In this study, we sought to understand how the relationship between NPs and a pharmacist and the physicians working in a family practice in rural Ontario evolved over time. These practitioners were required to adapt to their new collaborative team as well as implement a program of care.

Results highlight that effective teamwork is not a simple undertaking and that time (roughly 6 months) is required to have the team reach a moderately functioning capacity in which practitioners have a good working relationship, trust, and understanding of each others' roles. However, even at 15 months, the APTCare team members were still not fully integrated into the practice. The temporary nature of the intervention and the fact that the team members were required to work together only for the care of a select number of patients may have been barriers to team development. The inability to share a common geographical location within the building limited casual and informal interactions, likely preventing APTCare team members from being further integrated in the family practice.

Supporting the findings of other studies, we observed that FPs who had little prior collaboration experience with NPs initially experienced difficulty understanding the boundaries of the role, practitioner competence and capabilities, and issues of liability. ${ }^{56,57}$ Lack of understanding of scope of practice and practitioner competence is a recurring theme in many studies of interprofessional care. ${ }^{58-61}$ This study demonstrates that when role is better defined, as it was at the 6-month point, physicians had less concern about NPs' scope of practice and liability. ${ }^{62}$

Team synergy between the pharmacist and FP was there from the beginning. This may be because there is much less overlap between the roles of these practitioners and the pharmacist filled an immediately perceivable gap for the physicians. Despite "growing pains" while integrating the APTCare team, the practice saw the benefit of the interdisciplinary team through this study. They applied to the Ontario Ministry of Health and LongTerm Care for funding to transition into a Family Health Team, a practice model characterized by an interprofessional primary health care team working in a capitation remuneration payment model. The NPs involved in the APTCare intervention were all offered positions on the newly formed team.

Our qualitative findings revealed that once the initial program was in place and trust building was underway, physicians believed that having the NPs working with their more complex patients saved them time. This finding was unexpected because when we examined service use by APTCare patients, we did not find a reduction in appointments with physicians. ${ }^{63}$ The difference may arise from the transfer of coordination tasks from FP to NPs. Our NPs frequently took over care coordination duties, including writing referrals, organizing home care, and coordinating care with external practitioners (foot care, geriatric care, etc.), which would free physicians from some of these tasks. Although NPs brought with them advanced knowledge and skills of health assessment, strong chronic disease management, health promotion, and illness prevention, FPs really valued their coordination of patient care. This is indicative of a lack of full integration of NPs and their skills within the team.

Our focus on providing extra practitioner support to those patients who needed it most, rather 
than those who need it least, offers a reversal of the traditional integration of NPs and allied health professionals in primary care settings, which traditionally has centered on healthy patients of the practice, well-baby visits, patients with minor acute illnesses, or patients with stable chronic diseases. In this project, the NPs were caring for medically complex patients with the physicians in a shared care model. ${ }^{64}$ Despite this difference in the targeted patient population, our findings regarding team function, communication, and the integration of new team members are similar to that of the wider literature about interprofessional teams. Our research suggests that the challenges of collaborative relationships are independent of the type of patient population cared for by the NP. A long adjustment period will always be present, during which practitioners develop a working relationship, trust, and an understanding of each other's competencies and specializations.

\section{Conclusion}

This study described the development of collaborative relationships between APTCare team members (NPs and a pharmacist) and FPs working in a primary health care setting. Placed contextually within the current literature about team-based care, our research demonstrates that that the difficulties in bringing together a team and truly integrating practitioners are independent of the type of patient population. Regardless of patient population and sector of health care, developing collaborative relationships and learning to work collaboratively is difficult and takes time. Policymakers, managers, and practitioners should not assume that the development of collaborative relationships can happen quickly. In addition, it is not enough for public policy to add additional practitioners to practices, expecting collaboration to take root on its own. Many of these teams need ongoing support and education about how to make these collaborative care practices work.

\section{References}

1. Hutchison B, Levesque JF, Strumpf E, Coyle N. Primary health care in Canada: systems in motion. Milbank Q 2011;89:256-88.

2. Ontario Ministry of Health and Long Term Care. How family health teams work. Last updated April 26, 2011. Available at http://www.health.gov.on.ca/ transformation/fht/fht_work.html. Accessed January 23, 2012.

3. Ontario Ministry of Health and Long Term Care. Family health teams. Last modified April 26, 2011. Available at http://www.health.gov.on.ca/transformation/ fht/fht_mn.html. Accessed January 23, 2012.

4. Australian Government, Department of Health and Aging. Towards a national primary health care strategy: a discussion paper from the Australian government. 2008. Available at http://www.health.gov.au/ internet/main/publishing.nsf/content/d66fee14f736a $789 \mathrm{ca} 2574 \mathrm{e} 3001783 \mathrm{c} 0 /$ \$file/discussionpaper.pdf. Accessed January 23, 2012.

5. Bulletin of the World Health Organization. Flawed but fair: Brazil's health system reaches out to the poor. Available at http://www.who.int/bulletin/volumes/86/ 4/08-030408/en/index.html. Accessed February 5, 2012.

6. UK Department of Health. Delivering primary care. Last modified May 13, 2010. Available at http:// www.dh.gov.uk/en/Aboutus/HowDHworks/DH_ 074639. Accessed January 23, 2012.

7. Thylefors I, Persson O, Hellstrom D. Team types, perceived efficiency and team climate in Swedish cross-professional teamwork. J Interprof Care 2005; 19:102-14.

8. Zwarenstein M, Reeves S, Perrier L. Effectiveness of pre-licensure interprofessional education and postlicensure collaborative interventions. J Interprof Care 2005;19(Suppl 1):148-65.

9. Makowsky MJ, Schindel TJ, Rosenthal M, Campbell K, Tsuyuki RT, Madill HM. Collaboration between pharmacists, physicians and nurse practitioners: a qualitative investigation of working relationships in the inpatient medical setting. J Interprof Care 2009; 23:169-84.

10. Manser T. Teamwork and patient safety in dynamic domains of healthcare: a review of the literature. Acta Anaesthesiol Scand 2009;53:143-51.

11. Finley PR, Rens HR, Pont JT, et al. Impact of a collaborative care model on depression in a primary care setting: a randomized controlled trial. Pharmacotherapy 2003;23:1175-85.

12. Cook G, Gerrish K, Clarke C. Decision-making in teams: issues arising from two UK evaluations. J Interprof Care 2001;15:141-51.

13. Dieleman SL, Farris KB, Feeny D, Johnson JA, Tsuyuki RT, Brilliant S. Primary health care teams: team members' perceptions of the collaborative process. J Interprof Care 2004;18:75-8.

14. Nuñez DE, Armbruster C, Phillips WT, Gale BJ. Community-based senior health promotion program using a collaborative practice model: the Escalante Health Partnerships. Public Health Nurs 2003; 20:25-32.

15. Isetts BJ, Brown LM, Schondelmeyer SW, Lenarz LA. Quality assessment of a collaborative approach for decreasing drug-related morbidity and 
achieving therapeutic goals. Arch Intern Med 2003;163:1813-20.

16. Farris KB, Côté I, Feeny D, et al. Enhancing primary care for complex patients. Demonstration project using multidisciplinary teams. Can Fam Physician 2004;50:998-1003.

17. Humbert J, Legault F, Dahrouge S, et al. Integration of nurse practitioners into a family health network. Can Nurse 2007;103:30-4.

18. San Martin-Rodriguez L, Beaulieu MD, D'Amour D, Ferrada-Videla M. The determinants of successful collaboration: a review of theoretical and empirical studies. J Interprof Care 2005;19(Suppl 1): 132-47.

19. Pugh LC, Tringali RA, Boehmer J, et al. Partners in care: a model of collaboration. Holist Nurs Pract 1999;13:61-5.

20. Brock KA, Doucette WR. Collaborative working relationships between pharmacists and physicians: an exploratory study. J Am Pharm Assoc 2003;44: $358-65$.

21. Zillich AJ, McDonough RP, Carter BL, Doucette WR. Influential characteristics of physician/pharmacist collaborative relationships. Ann Pharmacother 2004;38:764-70.

22. Belanger E, Rodriguez C. More than the sum of its parts? A qualitative research synthesis on multi-disciplinary primary care teams. J Interprof Care 2008; 22:587-97.

23. Sargeant J, Loney E, Murphy G. Effective interprofessional teams: "contact is not enough" to build a team. J Contin Educ Health Prof 2008;28:228-34.

24. Suter E, Arndt J, Arthur N, Parboosingh J, Taylor E, Deutschlander S. Role understanding and effective communication as core competencies for collaborative practice. J Interprof Care 1999;23:41-51.

25. Axelsson SB, Axelsson R. From territoriality to altruism in interprofessional collaboration and leadership. J Interprof Care 2009;23:320-30.

26. O'Leary KJ, Ritter CD, Wheeler H, Szekendi MK, Brinton TS, Williams MV. Teamwork on inpatient medical units: assessing attitudes and barriers. Qual Saf Health Care 2010;19:117-21.

27. Hansson A, Friberg F, Segesten K, Gedda B, Mattsson B. Two sides of the coin - general practitioners' experience of working in multidisciplinary teams. J Interprof Care 2008;22:5-16.

28. Health Council of Canada. Rekindling reform: health care renewal in Canada, 2003-2008. 2009. Available at http://healthcouncilcanada.ca/en/index. php? page $=$ shop.product_details\&flypage $=$ shop.flypage $\&$ product_id=92\&category_id=14\&manufacturer_id= $0 \&$ option $=$ com_virtuemart $\&$ Itemid $=170$. Accessed January 23, 2012.

29. Atwal A, Caldwell K. Nurses' perceptions of multidisciplinary team work in acute health-care. Int J Nurs Pract 2006;12:359-65.

30. Roy D, Sylvain H. [Nursing practice in family medi- cine groups and its interdisciplinary context.] [Article in French.] Perspect Infirm 2004;2:16-20, 22-4, 26.

31. Arksey H, Snape C, Watt I. Roles and expectations of a primary care team. J Interprof Care 2007;21: 217-9.

32. Grumbach K, Bodenheimer T. Can health care teams improve primary care practice? JAMA 2004; 291:1246-51.

33. Pottie K, Farrell B, Haydt S, et al. Integrating pharmacists into family practice teams: physicians' perspectives on collaborative care. Can Fam Physician 2008;54:1714-7.

34. Morrison S. A case study of interprofessional learning and working at Marylebone Health Centre. Work Based Learning in Primary Care 2006;4:116-29.

35. Shaw A, de Lusignan S, Rowlands G. Do primary care professionals work as a team? A qualitative study. J Interprof Care 2005;19:396-405.

36. Fernandez R, Tran DT, Johnson M, Jones S. Interdisciplinary communication in general medical and surgical wards using two different models of nursing care delivery. J Nurs Manag 2010;1:265-74.

37. Solheim K, McElmurry BJ, Kim MJ. Multidisciplinary teamwork in US primary health care. Soc Sci Med 2007;65:622-34.

38. Goldman J, Meuser J, Rogers J, Lawrie L, Reeves S. Interprofessional collaboration in family health teams: an Ontario-based study. Can Fam Physician 2010;56:e368-74.

39. Hall P. Interprofessional teamwork: professional cultures as barriers. J Interprof Care 2005;19(Suppl 1):188-96.

40. Main R, Dunn N, Kendall K. Crossing professional boundaries: barriers to the integration of nurse practitioners in primary care. Educ Primary Care 2007; 18:480-7.

41. Tallia AF, Lanham HJ, McDaniel RR Jr, Crabtree BF. 7 characteristics of successful work relationships. Fam Pract Manag 2006;13:47-50.

42. Vanclay L. Teamworking in primary care. Nurs Stand 1998;12:37-8.

43. Dahrouge S, Hogg W, Lemelin J, Liddy C, Legault F. Methods for a study of anticipatory and preventive multidisciplinary team care in a family practice. Can Fam Physician 2010;56:e73-e83.

44. Friedmann PD, Jin L, Karrison TG, et al. Early revisit, hospitalization, or death among older persons discharged from the ED. Am J Emerg Med 2001;19: 125-9.

45. Jensen GL, Friedmann JM, Coleman CD, Smiciklas-Wright H. Screening for hospitalization and nutritional risks among community-dwelling older persons. Am J Clin Nutr 2001;74:201-5.

46. Jordan K, Ong BN, Croft P. Previous consultation and self-reported health status as predictors of future demand for primary care. J Epidemiol Community Health 2003;57:109-13. 
47. Meldon SW, Mion LC, Palmer RM, et al. A brief risk-stratification tool to predict repeat emergency department visits and hospitalizations in older patients discharged from the emergency department. Acad Emerg Med 2003;10:224-32.

48. Natarajan S, Nietert PJ. Hypertension, diabetes, hypercholesterolemia, and their combinations increased health care utilization and decreased health status. J Clin Epidemiol 2004;57:954-61.

49. Shelton P, Sager MA, Schraeder C. The Community Assessment Risk Screen (CARS): identifying elderly persons at risk for hospitalization or emergency department visit. Am J Manag Care 2000;6:925-33.

50. Hogg W, Lemelin J, Dahrouge S, et al. Randomized controlled trial of anticipatory and preventive multidisciplinary team care: for complex patients in a community-based primary care setting. Can Fam Physician 2009;55:e76-e85.

51. Way D, Jones L, Baskerville B, Busing N. Primary health care services provided by nurse practitioners and family physicians in shared practice. CMAJ 2001;165:1210-4.

52. Richards L. Using NVivo in qualitative research. London: SAGE Publications; 2002.

53. Boeije H. A purposeful approach to the constant comparative method in the analysis of qualitative interviews. Quality Quantity 2002;36:391-409.

54. Glaser B, Strauss A. The discovery of grounded theory: strategies for qualitative research. New York: Aldine Publishing Co.; 1967.

55. Denzin NK, Lincoln YS. Handbook of qualitative research. Thousand Oaks: Sage Publications; 1994.

56. Sullivan-Bentz M, Humbert J, Cragg B, et al. Supporting primary health care nurse practitioners' transition to practice. Can Fam Physician 2010;56: $1176-82$.

57. Thrasher C, Purc-Stephenson RJ. Integrating nurse practitioners into Canadian emergency departments: a qualitative study of barriers and recommendations. CJEM. 2007;9:275-81.

58. Horrocks S, Anderson E, Salisbury C. Systematic review of whether nurse practitioners working in primary care can provide equivalent care to doctors. BMJ 2002;324:819-23.

59. Kinnersley P, Anderson E, Parry K, et al. Randomised controlled trial of nurse practitioner versus general practitioner care for patients requesting "same day" consultations in primary care. BMJ 2000; 320:1043-8.

60. Laurant M, Reeves D, Hermens R, Braspenning J, Grol R, Sibbald B. Substitution of doctors by nurses in primary care. Cochrane Database Syst Rev 2005; (2):CD001271.

61. Sherwood G, Brown M, Fay V, Wardell D. Defining nurse practitioner scope of practice: expanding primary care services. Internet J Adv Nurs Pract 1997;1.

62. DiCenso A, Paech G, IBM Corporation. Report of the integration of primary health care nurse practitioners into the province of Ontario. Toronto, Ontario: Ministry of Health and Long-Term Care; 2003.

63. Gray D, Armstrong CD, Dahrouge S, Hogg W, Zhang $W$. Cost-effectiveness of anticipatory and preventive multidisciplinary team care for complex patients: evidence from a randomized controlled trial. Can Fam Physician 2010;56:e20-9.

64. Wilson A, Pearson D, Hassey A. Barriers to developing the nurse practitioner role in primary care: the GP perspective. Fam Pract 2002;19:641-6. 